8th Annual

\section{Whistler Winter Anaesthesia}

Refresher Course \& Review

February 27 - March 5, 1999

Whistier, British Columbia, Canada

21 hours CME credits

poster presentations

For information

Whistler Winter Anaesthesia Meeting

Department of Anaesthesia

Kingston General Hospital

76 Stuart Street

Kingston, Ontario, Canada, K7L 2V7

Voice Mail: (613) 549-6666 Ext. 3276

Fax: (613) 548-1375

E-mail: WWANAES@KGH.KARI.NET
PUERTORICO-CARIBBEAN SYMPOSIA

IN ANESTHESIOLOGYAND RELATED FIELDS

Plan Ahead

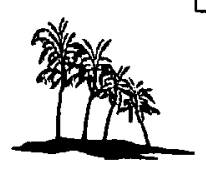

The 23rd Puerto Rico - Caribbean

Symposium in Anesthesiology

and Related Fields

Central Theme:

"Challenges for the Anesthesiologist

in the New Millennium"

Poster Sessions Scientific Exhibits and Optional Workshops on Regiona Blocks and Management of the Difficult Nirway. March 3-7, 1999

San Juan Marriott Resort

\& Stellaris Casino

San Juan, Puerto Rico

Meeting Sponsored by:

Department of Anesthesiology

Hospital del Maestro, San Juan, Puerto Rico and the

Puerto Rico Society of Anesthesiologists

For More Information Write:

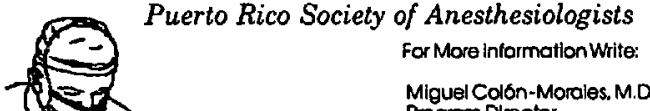

Progrom Director In Anestheslology and Related Fields

San Juan. Puerto Rico 00936-4547

Tel \& Fax: $(787) 758-9200$. Tal : $(787) 281-6673$

DON"T MISS IT! - TELL YOUR FRIENDS!

\title{
IWK Grace Health Centre for Children, Women and Families Career Opportunities in Paediatric Anaesthesia
}

The IWK Grace Health Centre is pleased to be able to offer an opening for a certified specialist in paediatric anaesthesia. The successful candidate will join 10 staff paediatric anaesthetists in an active and congenial academic group practice. The IWK Grace is a 400 bed children's and women's health centre affiliated with Dalhousie University. As the only tertiary paediatric centre in the Maritime region of Canada, the IWK Grace offers the full spectrum of tertiary care paediatric medical and surgical services including open heart surgery, neurosurgery, and renal transplantation. The Department of Anaesthesia provides a comprehensive operating room, deep sedation, pain, and critical care anaesthesia service to infants and children up to age 16. Members are active in graduate and undergraduate teaching as well as clinical and basic science research. The IWK Grace offers fully funded fellowship training opportunities in paediatric anaesthesia and critical care.

Remuneration to staff anaesthetists is offered through an alternate funding agreement with the provincial government which provides a guaranteed professional income with significant increments in each of the next three years.

Halifax is the capital city of Nova Scotia and the leading Maritime centre of trade, commerce, health care and education. A small but cosmopolitan city, Halifax is a popular place to live, raise a family, and enjoy life. The region is world renowned for its beauty and its cultural, educational and recreational opportunities. Reasonably priced housing is available in the immediate vicinity of the university and hospitals, and country or ocean-side living is possible with short commuting times.

Interested anaesthetists should contact

\author{
Dr. Chris Soder \\ Chief of Anaesthesia \\ IWK Grace Health Centre \\ 5850 University Avenue \\ Halifax NS B3J 3G9
}

Tel: (902) 4288031 Fax: (902) 4282911 E-mail: csoder@fox.nstn.ca 